The maintenance of these large and complex units introduces problems of a new scale in a physics laboratory. It creates the need for a new type of staff member, the 'technical officer'. He must be a trained physicist, in general a university graduate, but a man who has the engineer's outlook and who is interested in the construction and functioning of the apparatus rather than in the research which is done with it.

The radio group represents the continuation in the Laboratory of the work which Sir Edward Appleton started when he occupied the Jacksonian chair at Cambridge; it is now under the direction of Mr. J. A. Ratcliffe. It has field stations as well as its section of the main Laboratory. The work on propagation is mainly concerned with the longer wave-lengths which are reflected below the E-layer. Another section is making measurements of the waves in the metre wave-length region coming from the sun, recording their intensity and propagation and estimating the size of the source from which they come by a method analogous to Michelson's method of measuring the angular diameter of a star.

The Mond Laboratory is now under the direction of Dr. D. Shoenberg, its former head, Dr. J. F. Allen, having been recently appointed to St. Andrews. A main interest is the properties of superconductors, in particular the penetration of magnetic fields into superconductors. It has equipment for the magnetic method of cooling. Liquid helium is at present made by Kapitza's expansion machine; but a new machine of greater capacity and more orthodox type is under construction.

In crystallography, under Dr. W. H. Taylor, the arrangement of atoms in minerals, alloys, organic compounds and proteins is being studied. The section studying proteins under Dr. M. F. Perutz and J. C. Kendrew has this year been accorded the backing of the Medical Research Council. The elucidation of the structure of such enormous and complex molecules is the most ambitious problem as yet tackled by $\mathrm{X}$-ray analysis, and success would cast a flood of light on the structure of living matter.

The metal physics section, under Dr. E. Orowan, is concerned with problems of slip and plasticity, fracture, crystal growth, and metallic phenomena in general investigated by physical methods.

The Laboratory houses an electron microscope service which is used by all departments of the University. It provides hospitality for several researchers from other departments. Particularly welcome guests are the mathematical physicists, including the Plummer professor, D. R. Hartree, who have rooms in the Laboratory.

It may be of interest to assess in round figures the cost of research in the Cavendish Laboratory. The figures must be approximate, since many of the services are common to teaching and research. As an example, in the following estimate the time of the University staff is regarded as divided equally between teaching and research, and its cost apportioned accordingly. Making similar adjustments for administration, assistant staff, stores and apparatus (almost entirely research) and so forth, the total expenditure on research in the Laboratory (including the Mond) was just short of $£ 60,000$ in $1946-47$, of which $£ 10,000$ came from outside sources. To this must be added a sum to represent the rental of the buildings, which does not appear in the estimates. In estimating the cost per research student, the abnormal position of nuclear research must be taken into account. Not only are the running expenses above the average, but also units such as the cyclotron represent a large outlay of capital, and special grants are made by the Department of Scientific and Industrial Research to meet needs which the University cannot finance from its own resources. Such requirements vary very greatly from year to year, and I have therefore only included a sum for nuclear research which corresponds to the expenditure per researcher in other branches of physics, and which roughly represents the contribution which the University itself makes towards the cost of the nuclear research. On this basis, the cost per research student is $£ 400$ a year. If to this is added $£ 350$ to represent the average maintenance grant of junior and senior workers, the total cost to the State of maintaining a research worker in the Cavendish Laboratory is $£ 750$ a year.

\section{MAN'S ORGANS OF SPEECH}

7 HE Huxley Memorial Lecture for 1947, under the auspices of the Royal Anthropological Institute, was delivered by Dr. W. L. H. Duckworth, reader emeritus in human anatomy in the University of Cambridge. The subject was "Some Complexities of Human Structure"*. The approach was frankly anatomical and was a meticulous and masterful analysis of the facts, anatomical and racial, relating to the organs of speech in man. Duckworth wasted no time on the classical definitions of anthropology; he ignored the subdivisions of the subject and refused to be drawn into the finer distinctions of zoological anthropology, physical anthropology, social and cultural anthropology and ethnology. He kept clear of the pathological and avoided the theories of aphasia from Broca and Bastian to Henry Head. Here was the approach to the anatomical aspect as emphasized by Galen in his "Methodus Medendi" : "The magnitude of a disease is in proportion to its deviation from the healthy state; and the extent of the deviation can be ascertained by him only who is perfectly acquainted with the healthy state". Hence the justification for the intensive study of normal structure and function in man as distinct from booksellers' notes about positive health and social medicine.

Duckworth dealt in turn with our present knowledge of the anatomy of the organs of speech, from lips, tongue, jaw, palate to the component parts of the larynx and finally the brain. To listen to so distinguished an anatomist, who is also the doyen of physical anthropologists, survey the field, much of his own ploughing and harrowing, was an intellectual feast. Rarely has a lecturer given facts and their history, as T. H. Huxley demanded, and yet exposed the gaps in our knowledge in both anatomy and physical anthropology. His survey of the work to be done provided bone and grist for many young workers. Here surely was God's plenty for the young anatomist in the laboratory and the young anthropologist in the field. The survey from Cuvier's postulate that articulate speech was the distinctive character of man to the vast modern demands of phonetics, linguistics and psychology was a criticism and yet a stimulus to the biological study of the organs of speech, emphasis being laid on the need for perfect acquaintance with the healthy normal anatomical structure.

- Some Complexities of Human Structure. By Dr. W. L. H.
Puckworth. (Huxley Memorial Lecture for 1947.) Duckworth. (Huxley Memorial Lecture for 1947.) Pp. 12. (London:
Royal Anthropological Institute, 1947.) 3s, 6d. 
The description of the racial variation in the muscles of the lips in Australian, Negro, Chinese and White paid due credit to the careful dissections and theories of Huber in the United States and Lightoller in Australia. The gradual change from the coarsely bundled muscles of the bulky lip of the one to the finely bundled and more differentiated muscles of the smaller lip of the White was analysed both in terms of facial expression and speech. Duckworth insisted that the variety of movements accompanying the variety of structure are skilled, and saw no reason why they might not become more skilled in the future. It is interesting to note that this work of Lightoller's, ignored by most anatomists, was seized upon by Dr. E. W. Fish ${ }^{1}$ to modify the technique of fitting artificial teeth in the aged. Fish expanded the dentures laterally so that their position was maintained by the modiolus or hub formed by the converging muscles lateral to the angle of the mouth. The utilitarian aspects of transcendental research are ever present, whether it be the grouping of relatively minute and insignificant muscles in the face or the Hertzian waves.

That strange amateur anatomist, F. O. Ward ${ }^{2}$, in the middle of last century described the hyoid bone as "the only instance in the human body of a strictly solitary bone... supported in its position by the muscles and ligaments to which it gives insertion". The embryologist, immersed solely in the intricacies of the second and third branchial cartilages which contribute to the formation of the hyoid bone, has studied the early development of this bone. The possibility of changes in the structure of the hyoid bone with age, sex and vocal disability ranging from stammering to dumbness still awaits investigation. So far back as 1866, Huxley ${ }^{3}$ described the larynx in his famous "Lessons in Elementary Physiology" as "perhaps the most singular motor apparatus in the body". Yet, in spite of Edison's invention of the phonograph in 1877, and the spread of the gramophone and wireless broadcasting in the twentieth century, the Iarynx has been but little studied by the modern anatomist and physiologist. As Duckworth pointed out, the outstanding contribution of recent years has been the "Mechanism of the Larynx" by Negus", a book "absolutely indispensable for every physical anthropologist, and for the purpose of any research in laryngology, whether normal or pathological".

In 1833 a French surgeon, Cavasse ${ }^{4}$, pointed out that fracture of the thyroid cartilage, a result of garrotting, never takes place in the mid line, because the two lateral parts of the cartilage unite by the intervention of a median cartilage, perfectly conscribed, which Rambaud and Regnault ${ }^{5}$ called the vocal cartilage. It is visible by transillumination especially in young subjects, and gives attachment to the vocal cords. It is ossified from a separate centre, contains more elastic tissue in the young than the two lateral laminæ of the thyroid cartilage and affects the production of the voice. Yet Quain ${ }^{6}$ in 1914 was content with the statement that "in the infant the isthmus of the thyroid cartilage differs from the two laminæ in being less opaque and more flexible". All other anatomical text-books have been dumb on this complexity of human structure, particularly the more recent ones.

In the second century A.D., Galen gave a detailed description of the larynx, and for eighteen centuries the eponym 'nerve of Galen' has been employed for the constant anastomotic branch between the superior and inferior laryngeal nerves. Moreover, Galen first reported the experimental proof of the function of the recurrent laryngeal nerve of the vagus by tying or dividing the nerve and thus weakening or destroying the voice of the animal. Surely, as Benjamin Franklin said, "all our knowledge . . . has been obtained by fragments, and our future acquisitions must be made in the same manner".

This brief and inadequate description of Dr. Duckworth's Huxley Lecture provokes the remark that editorial articles in Nature discussing the functions of universities have failed to mention one, namely, to provide for a green old age for scholars and men of science. Little note has been taken that such provision requires an atmosphere devoted to the maintenance of mental activity, cheerful disposition, simplicity of living on one hand, and absence of business urge, desire for wealth, and all tawdry ambitions of worldly importance on the other. At a time when the universities are in danger of being monopolized by the search for smaller atoms, bigger bombs, and diabolical and destructive enzyme poisons, it is well to re-echo Montaigne's last prayer "to know how to enjoy with loyalty our life". As Tocqueville and Lecky tried to make clear, this may be the very basis of anthropology.

\section{H. A. HARRIS}

1 Fish, E. W. "Principles of Full Denture Prosthesis" (London, 1933). ${ }^{2}$ Ward, F. O., "Outlines of Human Osteology" (London, 1838).

"Huxley, T. H., "Lessons in Elementary Physiology" (London, 1866)。 " Cavasse, "Thèse sur les fractures traumatique du larynx" (Paris, 1833). s Rambaud, A., et Regnault, Ch., "Origine et développement des $0 \mathbf{s}^{\text {" }}$ (Paris, 1861).

-Quain, "Flements of Anatomy". 11th Edit., 2, Pt. 2 (London, 1914). "Negus, V. E., "The Mechanism of the Larynx" (London, 1929).

\section{INTERACTION OF WATER AND POROUS MATERIALS}

AENERAL Discussion of the Faraday Society $A$ on "The Interaction of Water and Porous Mater. ials" was held at University College, Southampton, during March 31-April 2. The four groups of papers on the programme were concerned with $(a)$ fundamental, (b) botanical, (c) zoological, mainly entomological, and $(d)$ industrial aspects of the penetration and movement of water in porous materials. They were well chosen to provide topics on which physical chemists, botanists, zoologists, agriculturists and those interested in fibrous materials such as textiles, wood and leather, could discuss problems common to two or more groups.

The factors governing the penetration of liquids into non-living capillary spaces, the diameter of which is greater than the range of molecular attraction, are fairly well understood. The penetration pressure, $P=2 \gamma \cos \theta / r$, where $\gamma$ is surface tension, $r$ is radius of the capillary considered as a cylinder, and $\theta$ is contact angle, determines the conditions of penetration; but the contact angle depends not only on the chemical nature of the solid and liquid, but also on the geometrical structure of the solid, and whether the liquid is advancing over a dry solid or receding from a wet one. The possible reasons for 'hysteresis of the contact angle', that is, the difference between the advancing and receding angles, received much attention; it was variously ascribed to roughness of the surface, overturning of the surface molecules, multi-molecular clusters of adsorbed water on the solid, films of air or other substances adhering 